Tjalling C. Koopmans Research Institute

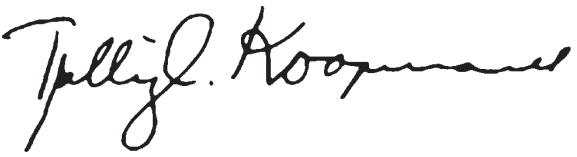

Discussion Paper Series nr: 08-10

\title{
The Importance of Financial Incentives on Retirement Choices: New Evidence for Italy
}

Michele Belloni

Rob Alessie 


\section{Tjalling C. Koopmans Research Institute Utrecht School of Economics \\ Utrecht University}

Janskerkhof 12

3512 BL Utrecht

The Netherlands

telephone $\quad+31302539800$

fax $\quad+31302537373$

website www.koopmansinstitute.uu.nl

The Tjalling C. Koopmans Institute is the research institute and research school of Utrecht School of Economics.

It was founded in 2003, and named after Professor Tjalling C. Koopmans, Dutch-born Nobel Prize laureate in economics of 1975.

In the discussion papers series the Koopmans Institute publishes results of ongoing research for early dissemination of research results, and to enhance discussion with colleagues.

Please send any comments and suggestions on the Koopmans institute, or this series to M.vanDort@econ.uu.nl

ontwerp voorblad: WRIK Utrecht

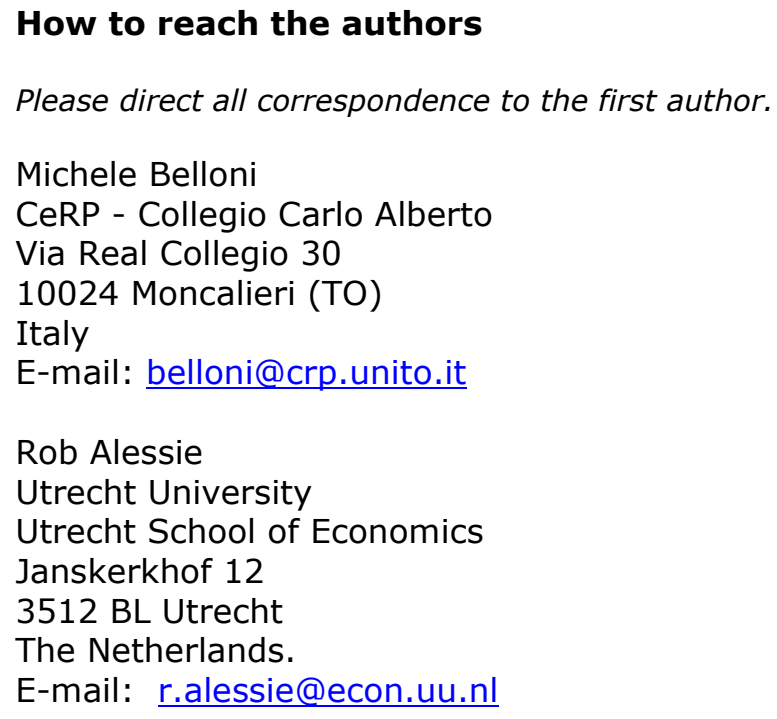

Please direct all correspondence to the first author.

Michele Belloni

CeRP - Collegio Carlo Alberto

Via Real Collegio 30

10024 Moncalieri (TO)

Italy

E-mail: belloni@crp.unito.it

Rob Alessie

Utrecht University

Utrecht School of Economics

Janskerkhof 12

3512 BL Utrecht

The Netherlands.

E-mail: r.alessie@econ.uu.nl 
Utrecht School of Economics

Tjalling C. Koopmans Research Institute

Discussion Paper Series 08-10

\title{
The Importance of Financial Incentives on Retirement Choices: New Evidence for Italy
}

\author{
Michele Bellonia \\ Rob Alessie

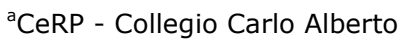 \\ Italy \\ bUtrecht School of Economics \\ Utrecht University
}

May 2008

\begin{abstract}
This study exploits a new dataset in order to quantify the effect of financial incentives on retirement choices. This dataset contains - for the first time in Italy information on seniority. In accordance with the general finding in Gruber and Wise (2004), we find that financial incentives have an effect on retirement. The effect goes in the expected direction; when employees become eligible for pension benefits the change in financial incentives they experience is so high that their retirement probability increases in a sizable way. We also find that the procedure to impute seniority used in previous studies leads to a sizable measurement error. Due to this measurement error, the key parameters of the model are inconsistently estimated. Our sensitivity analysis suggests that the lack of appropriate information on seniority is an important reason for the unclear evidence so far obtained in retirement studies for Italy.
\end{abstract}

Keywords: retirement, social security wealth, seniority, unobserved heterogeneity.

\section{JEL classification: $] 2$}

\section{Acknowledgements}

The authors thank Christopher Flinn, Elsa Fornero, Adriaan Kalwij, Maarten Lindeboom, Giovanni Mastrobuoni, Mauro Mastrogiacomo, Rute Mendes, Giovanna Nicodano, and Arthur van Soest for their useful comments. Moreover, the authors appreciate the comments made by the participants to the NETSPAR conference Pensions, Saving and Retirement Decisions, to the seminar at Collegio Carlo Alberto and to the conference Labor Market Flows, Productivity and Wage Dynamics: Ideas and Results from Empirical Research on EmployerEmployee Linked Longitudinal Databases. All opinions and errors are those of the authors alone. They also thank the 'Laboratorio Revelli' (www.laboratoriorevelli.it) for the provision of the data. 


\section{Introduction}

One of the most relevant changes in the dynamics of the labor force in industrialized countries since the '60s has been the decline in the participation rates of older workers. The labor force participation rate of males aged 60-64 in EU, for example, dropped in the period 1960-2007 from 70 to 37 percent (?). In some countries, namely Belgium, France, Italy and The Netherlands, the rate fell well below 20 percent by the mid-'90s (?). Together with the increase in the old-age dependency ratio caused by population aging, earlier retirement is considered the main cause of the current crisis of PAYGO pension schemes.

In order to alleviate the financial burden imposed on their social security balance, many countries have recently implemented reforms often aimed at increasing the retirement age. Compared to benefits cuts or payroll taxes increments, the increase in the retirement age is potentially more effective, since it can improve both sides of the balance. Its actual effectiveness depends on whether and how much workers react to social security financial incentives. Therefore, understanding the role of financial incentives in retirement choices is crucial for a good policy design.

In this study, we use a panel dataset covering the period 1985-2001 to analyze the impact of financial incentives provided by the social security system on workers' retirement choices in Italy. We adopt the methodology in ? and estimate a quasi-reduced form model in which the probability for a worker to retire is explained by financial incentives, in addition to personal characteristics. The worker is assumed to be forward-looking. At each age she computes her current social security wealth (SSW). Due to an income effect, the higher her SSW the higher her retirement probability. Furthermore, on the basis of her expected earnings and the expected features of the social security system, she computes her SSW associated with retiring at alternative future ages. She then compares them with her current SSW and, if they are lower, its more likely that she leaves the labor market. Therefore, her global (SSW) and marginal incentives (MI), i.e. the current level and the expected change of her SSW, determine together her retirement choice. The model is dynamic, since the retirement choice is reconsidered year after year as new information affecting her financial incentives becomes available. The decision procedure continues until she actually retires, since retirement is an absorbing state. 
? collect recent applications of this type of models. This work gathers twelve country studies and, although each of them is independent from the others, it compares the results thanks to a common econometric methodology. Its general finding is a strong causal effect of financial incentives on retirement. However, Italy (see ?) shows a weak evidence of this, both for SSW and MI measures, representing thus a noticeable and puzzling exception. The weakness of results for Italy is confirmed in a later study (?), where no significant effect for MI measures is found $1 \frac{1}{1}$ An unclear picture emerges also from other studies (see e.g. ?, ?, ?).

These ambiguous findings might be surprising at first sight because Italy underwent several pension reforms during the '90s. One would expect that such reforms would lead to considerable changes in SSW and marginal incentives to retire. This variation should help to identify the parameters of interest, as ? and ? claim. Most Italian studies have used data which stems from the O1M administrative archive managed by INPS.2 In this dataset, seniority, i.e. the number of years the worker has contributed to the pension scheme, is unknown. Unfortunately, this information is crucial to compute pension benefits and eligibility. A way to impute seniority would be simply counting the number of years the worker contributes to the pension scheme. However, even though the O1M samples span a long period? the whole contribution history in the pension scheme is typically not observed. Strong assumptions and other data sources such as the SHIW are required to impute the variable 'seniority', see e.g. ? for more details about the imputation procedure.

Like ? and ?, we identify the key parameters of the model by exploiting the time variation in the SSW and MI measures which stems from the pension reforms mentioned above. Moreover, this study combines a new longitudinal dataset, the 'Working History Italian Panel' (WHIP), with an additional pension file which provides information on seniority. Consequently,

\footnotetext{
${ }^{1}$ The only exception to this result is given by the 'option value' measure, which is found to significantly affect males retirement choices. On the other hand, for females the authors find no effect of SSW on retirement.

${ }^{2}$ Before the INPS data became available, research on retirement for Italy (see e.g. $?, ?, ?)$ relied on the Bank of Italy's survey SHIW. Unfortunately, in this survey seniority (consider e.g. fig. A4 in ?) and earnings are measured imprecisely. Moreover, its sample size is rather small compared to the INPS data. Therefore, the SHIW survey is not used anymore to analyze retirement behavior.

${ }^{3}$ For instance, the dataset used by ? covers the period 1973-1997.
} 
in comparison with previous studies we can measure SSW and MI with greater precision.

Our empirical analysis indicates that financial incentive variables are strongly significant and affect retirement in the expected direction. Results are robust to different assumptions about e.g. wage expectations and in line with the general findings reported in ?. We will also show that the imputation procedures used in previous studies may lead to a sizable measurement error in the variable 'seniority'. Consequently, estimates of the key parameters of the model are inconsistent: if we use the imputed measure for seniority instead of the observed one, the estimate of the SSW parameter gets the wrong sign. Moreover, the marginal effect of the MI variables on the retirement probability becomes much smaller in magnitude.

A second contribution of the paper is that our econometric model takes into account individual unobserved heterogeneity. Individuals might differ in their preferences for reasons not observed by the econometrician. In panel data models, such differences are typically captured by a so-called individual effect. Although panel data are often available, most other studies on retirement choice do not include individual effects in their models (?). As a result, they ignore a potential dynamic sample selection bias problem. This bias may arise because workers with stronger preference for work will stay in the sample for a longer time.

Including individual unobserved heterogeneity raises another identification issue. As ? highlight, individual effects and financial incentive variables can be correlated. For example, a work-lover worker may tend to have high SSW and low retirement probability. We use the methodology put forward by ? in order to take into account these correlations $4^{4}$ Basically, we extend the random effect probit model explaining transition into retirement by including as extra regressors financial incentives in the first year each worker is observed. As a result, the financial incentive parameters are identified exploiting within-individual variation.

The paper proceeds are follows. Section 2 gives an overview of the Italian institutional framework. Sections 3 and 4 describe the data characteristics and the sample selection. Section 5 defines the financial incentives and illustrates the main assumptions made in their computation. Section 6 describes

\footnotetext{
${ }^{4}$ ? investigates the relation between private wealth and retirement choice. He uses an alternative methodology to take into account (correlated) unobserved heterogeneity.
} 
the retirement model. Section 7 highlights the main results. Section 8 concludes. An appendix provides additional details on the computation of SSW A.1) and the wage modeling A.2.

\section{Institutional framework}

\subsection{Overview}

Up to the '90s, the Italian social security system was financially unsustainable, characterized by extremely favorable early retirement schemes with no actuarial adjustments and by generous pension formulae granting often 70-80 percent of the worker's last wage. The existence of different rules for different categories of workers, and of many exceptions to the general rules generated an implicit and often perverse redistribution of resources.

In the '90s, the whole system has been highly redesigned in order to restore its financial sustainability. To this aim, there have been two remarkable reforms, in 1992 and in 1995, and several other laws. The 1992 reform induced a drastic reduction in SSW due to the fact that the indexation mechanism of the outstanding pensions changed from wage-based to price-based. The 1995 reform has been the most radical, modifying the pension formula from a defined benefit into a (notional) defined contribution-type, but less effective in the short run because applied only to young workers 5 Most of the new rules have been introduced gradually, generating a continuously changing normative environment.

Currently, about two-thirds of the workforce is insured with INPS, the main social security institute in the private sector (see ?). The FPLD ('Fondo Pensioni Lavoratori Dipendenti') is the INPS main pension scheme, and enrols almost all employees. Separate schemes managed by INPS exist for the self-employed and for other categories of workers. Although an attempt has been made to harmonize the different schemes, the legislation is still extremely fragmented. Given the scope of the paper, and considering the complexity of the framework generated by the reforms, we only describe the rules affecting older workers enrolled in the FPLD fund. We first illustrate old-age and seniority pensions, which represent the main exit paths

\footnotetext{
${ }^{5}$ For this reason, the DC formula introduced by the 1995 reform is not considered in our analysis. More details on this formula and on the institutional framework for older workers can be found in ?.
} 
to retirement. Then we discuss other social security programs targeted to older workers.

\section{$2.2 \quad$ Old-age and seniority pensions}

The expenditure for old-age and seniority pensions has represented the most relevant item in the INPS balance sheet in the last decades, being around 70 percent of the total expenditure on newly awarded FPLD pensions $(?, ?)$. Because of its eligibility criteria, the old-age pension has been the favorite exit route for workers with more discontinuous working careers (typically females). Seniority pensions have instead been intensively exploited by males. In our sample 72 percent of the retiring females claimed an old-age pension, whereas 83 percent of the retiring males started to receive a seniority pension.

In the pre-reform period, eligibility requirements for old-age and seniority pensions were extremely favorable. Males and females could claim an oldage pension at age 60 and 55 respectively, once they had accrued 15 years of seniority. A seniority pension could instead be claimed with 35 years of accrued seniority, regardless of age.

The legislative process of the '90s, however, made the access to these benefits much tighter. The 1992 reform, followed by another law in 1994, progressively raised requirements for the old-age pension by 5 years. The 1995 reform restricted the access to the seniority pension, by progressively increasing minimum seniority up to 40 years and by introducing the 'exit windows' mechanism. According to it, workers could claim a seniority pension only at some fixed dates during the year, thus resulting in a delay of 3-12 months in their actual retirement date. Some ad-hoc laws, introduced to avoid massive exits caused by a fear of further tightenings of eligibility requirements, even blocked the access to seniority pensions in 1993 and 1995. The 1995 reform introduced an additional requirement for the seniority pension, based on a (increasingly tougher) combination of age and seniority. The transition to the tougher rules for white collars was then made shorter by a law in 1997. The progressive increase in minimum requirements for old-age and seniority pensions generated by the reforms of the '90s is illustrated in table 1 .

The computation formula of old-age and seniority pensions is given by the product of three factors: pensionable earnings, seniority and annual re- 
Table 1: Eligibility requirements for old-age and seniority pensions

\section{Old-Age \\ Seniority}

(a)

\begin{tabular}{|c|c|c|c|c|c|c|}
\hline \multirow[t]{2}{*}{ Year } & \multicolumn{2}{|c|}{ Age } & \multirow{2}{*}{$\begin{array}{c}\text { Sen. } \\
\text { All }\end{array}$} & \multirow{2}{*}{$\begin{array}{l}\text { Age } \\
\text { All }\end{array}$} & \multirow{2}{*}{$\begin{array}{c}\text { Sen. } \\
\text { All }\end{array}$} & \multirow{2}{*}{$\begin{array}{c}\text { Sen. } \\
\text { All }\end{array}$} \\
\hline & Males & Females & & & & \\
\hline 1985-1992 & 60 & 55 & 15 & - & - & 35 \\
\hline 1993 & 60 & 55 & 16 & - & - & 35 \\
\hline 1994 & 61 & 56 & 16 & - & - & 35 \\
\hline 1995 & $61^{a}$ & $56^{a}$ & 17 & - & - & 35 \\
\hline 1996 & 62 & 57 & 17 & 52 & 35 & 36 \\
\hline 1997 & 63 & 58 & 18 & 52 & 35 & 36 \\
\hline 1998 & $63^{b}$ & $58^{b}$ & 18 & $54^{c}$ & 35 & 36 \\
\hline 1999 & 64 & 59 & 19 & $55^{d}$ & 35 & 37 \\
\hline 2000 & 65 & 60 & 19 & $55^{c}$ & 35 & 37 \\
\hline 2001 & 65 & 60 & 20 & $56^{d}$ & 35 & 37 \\
\hline $2002-2003$ & 65 & 60 & 20 & $57^{d}$ & 35 & 37 \\
\hline 2004-2005 & 65 & 60 & 20 & $57^{c}$ & 35 & 38 \\
\hline 2006-2007 & 65 & 60 & 20 & $58^{c}$ & 35 & 39 \\
\hline$>2007$ & 65 & 60 & 20 & $58^{c}$ & 35 & 40 \\
\hline
\end{tabular}

Notes: a. born before $1 / 7 / 34$ if male, born before $1 / 7 / 39$ if female; $b$. born before $1 / 7 / 35$ if male, born before $1 / 7 / 40$ if female; $c$. 1 year younger if blue collar; $d$. 2 years younger if blue collar.

turn. Pensionable earnings are the average wage of the last years of work, where past wages are updated to account for inflation. Seniority includes the years of regular contribution to the scheme as well as the years of "notional' contribution made during temporary out of work periods (e.g. unemployment spells, maternity leaves and military service). Up to 40 years of seniority are accounted for in the pension formula, and therefore staying longer in the labor market is highly discouraged. The annual return is a decreasing function of (non-capped) pensionable earnings, equal to 2 percent for the lowest earning bracket ${ }^{6}$ The minimum annual return is equal to 0.9 percent.

The three components of the pension formula have been modified dramatically by the reforms of the '90s. The most important change has been the progressive increase from 5 to 10 in the number of years included in the computation of pensionable earnings. Due to this change in the law,

${ }^{6}$ This bracket is rather wide: incomes between 0 and $40725 €$ fall in it. 
especially the highly educated employees faced a reduction in their social security wealth because their age-wage profile is typically upward sloping.

In case the formula implies a pension benefit which is lower than a threshold amount (the 'minimum pension'), the claimant receives an extra benefit in order to fill this gap provided he/she passes an earning test. Due to the rule of lower returns for higher pensionable earnings and due to the provision of a minimum pension, the Italian pension system is highly progressive. Full retirement is not compulsory for pension claiming: pension beneficiaries are allowed to work. However, in that case pension income is subject to a high tax rate which makes this option rather unattractive. As a consequence, only a very small fraction of pension beneficiaries (less than 5 percent, according to our data) remains at work.

Payroll tax rates, which grew from 25.21 to 32.7 percent of the wage in the period under analysis, are shared between the employer (who pays twothirds) and the employee. These contributions are deductable from taxable income whereas pension benefits are subject to personal income taxation. Employees pay an additional 7.41 percent payroll tax to a severance-pay fund ('Trattamento di Fine Rapporto'). This sum, administrated by the employer, gives a return fixed by law and provides a lump-sum payment when the employee leaves the firm.

\subsection{Other social security programs}

Other social security programs providing sources of income for older workers and sometimes used as early retirement schemes are survivors benefits, disability pensions and unemployment benefits.7

Survivor benefits are paid to the worker's relatives, including the widow(er), minor or disabled children, children in full-time education or, in particular cases, even parents or brothers and sisters. The amount of the survivor benefits depends on the number of donees and on their earnings.

Until the mid-'80s disability pensions have been very often used as an early retirement scheme. In the period 1975-1980 the share of disability benefits reached a peak of almost 40 percent of total social security benefits

\footnotetext{
${ }^{7}$ Individuals aged 65 with no contribution history and low income are eligible for the social pension ('pensione sociale'), a kind of maintenance income program. Given that the social pension only concerns individuals without or with a very limited work history, it is not of direct interest for this study.
} 
in the FPLD fund (see ?). Eligibility for this benefit was in fact based on a rather vague concept, the 'loss of earnings ability', i.e. the incapacity to earn at least one-third of the current income. This vagueness resulted in a great degree of discretionally by doctors in their diagnosis. At the same time, the worker had a strong incentive to claim this benefit, given that its computation was the same as for old-age or seniority pensions.

The situation dramatically changed after the 1984 reform. This law aimed at reducing the phenomenon of 'false' disabled and acted in two directions. First, it introduced a much tougher eligibility requirement: the permanent impossibility of doing any kind of working activity 8 Second, the screening of medical conditions was made more frequent, and with random checks. As a result, the flow of disability pensions - especially in the age range 50-59, where these benefits were used as an early retirement scheme diminished drastically and quickly (?).

Unemployment programs targeted to older workers are the so-called 'prepensionamento' and the mobility scheme ('mobilità'). The former is an early retirement scheme granted to older workers in firms going through a recessional phase. This scheme was intensively used in the ' 80 s and rarely used afterward. Only firms belonging to specific sectors were eligible to this support of the government. The mobility scheme, introduced in 1991, is a subsidy granted to workers of any age who are collectively fired by firms in a recessional phase. Its general aim is to favor workers' reemployment in the labor market. However, older employees can sometimes use this scheme as a 'bridge' to the old-age pension ('mobilità lunga') if they live in areas characterized by high unemployment?

\section{Data}

Our analysis is based on the 'Working History Italian Panel' data (WHIP), a random sample drawn from an administrative archive managed by INPS. This longitudinal dataset covers the period 1985-2002. WHIP includes one-

\footnotetext{
${ }^{8}$ The concept of 'loss of earnings ability' was changed by the law in 'loss of working ability' and became a requirement for a new subsidy: the disability check ('assegno ordinario di invalidità'). This check is much less attractive than the disability pension because its amount is lower and because it lasts three years and is renewable only after a new medical check.

${ }^{9}$ Standard unemployment benefits are also sometimes used to finance early retirement.
} 
ninetieth of the private sector, non-agricultural workforce. It contains data on 315 thousand workers. Since workers enter and exit the archive at any time, the panel is unbalanced.

WHIP consists of the O1M data (the archive used in previous studies) and of other complementary files. The O1M data focuses on the private sector employees and contains information on wages, weeks worked, occupation, type of contract and other working spell characteristics. The complementary files provide data on spells of self-employment (artisans and traders), atypical work, unemployment and mobility. For these spells the related earnings (or subsidies) are observed 10

WHIP also collects information on the pensions paid, such as dates of payment and amounts. Unfortunately, it does not provide any data on seniority. However, information on seniority accrued at retirement is available in another INPS pension file 11 Notice that seniority is not observed for workers who did not receive any pension benefit, either because they are too young or because their careers have been characterized by long interruptions or contributions have been made to other schemes (e.g the public sector). Seniority is available for pensions paid in the period 1985-2006.

One weakness of our data is the partial coverage of the workforce: neither the public nor the agricultural sector are included. In addition, the dataset only provides information on few individual characteristics (gender, date and region of birth). Household variables, such as the earnings of the partner, are not observed. Finally, earnings from self-employment are noisily measured.

From table 2 it becomes clear that our dataset is much more informative than the O1M dataset used in previous studies. Notably, actual seniority and more types of transitions in the labor market are observed. As said before, previous studies had to make some strong assumptions in order to construct the variable 'seniority'. Such a constructed variable is riddled with measurement error. Obviously, this may have also affected the computation of financial incentives. In order to assess the extent of this measurement

\footnotetext{
${ }^{10}$ Atypical work contracts are short-term contracts characterized by a favorable payroll tax treatment. Since 1996 INPS manages contributions and pensions rights of these contracts in a special fund.

${ }^{11}$ In order to compute financial incentives we need to know accrued seniority in each year (and not only at retirement). Nevertheless, by exploiting the O1M data, we recover the precise accrued seniority in each year by backward subtracting from seniority at retirement the number of weeks worked. Moreover we use the unemployment and the mobility files to subtract the number of weeks in which notional contributions have been granted.
} 
Table 2: A comparison between the O1M and our data

\begin{tabular}{lcc}
\hline & Our data & O1M data \\
\hline Eligibility requirements: & & $x$ \\
Seniority at retirement & $\checkmark$ & $x$ \\
Notional contributions & $\checkmark$ & \\
\hline Transitions into retirement: & & \\
Self-empl: artisans and traders & $\checkmark$ & $x$ \\
Atypical workers & $\checkmark$ & $x$ \\
Private sector pensioners & $\checkmark$ & $x$ \\
Unemp. and mobility benefic. & $\checkmark$ & $x$ \\
Self-empl: farmers & $x$ & $x$ \\
Public sector & $x$ & \\
\hline
\end{tabular}

error problem, we use our data to replicate the imputation procedure used in previous studies 12

We first use the Bank of Italy's survey SHIW (cross-sections for various years) to compute the average age of entry into the labor market by gender and occupation for similar cohorts as in our dataset. We then impute this average to each worker according to her characteristics. Due to the assumption of a continuous career, we are able to compute seniority as the difference between age and the imputed age of entry into the labor market 13 Table 3 shows that in case of blue collar workers the imputed seniority is on average much higher than the actual one. Moreover, the standard deviation of the imputed measure is much lower. The standard deviation of the measurement error in seniority is sizable in our data (see column 'Difference, s.d.').

Another potential improvement of our dataset is that more types of labor market transitions can be distinguished. Due to this information, the actual retirement status of each individual can be measured in a more precise way. Previous studies have assumed that workers were retired when they have permanently left the O1M archive. Relying on the WHIP complementary files, we can relax this assumption. We observe whether and when a private sector employee became an artisan, trader or atypical worker. ? state that

\footnotetext{
${ }^{12}$ In section 7 we assess how the measurement error problem affects the computation of financial incentives and the econometric results.

${ }^{13} \mathrm{We}$ admit that we might overstate the measurement error problem because other authors have used a panel with a larger time dimension than us.
} 
Table 3: Imputed versus actual seniority

\begin{tabular}{lcccccc}
\hline & \multicolumn{5}{c}{ Seniority (years) } \\
& \multicolumn{2}{c}{ Actual } & \multicolumn{2}{c}{ Imputed } & \multicolumn{2}{c}{ Difference } \\
\hline group & average & s.d. & average & s.d. & average & s.d. \\
\hline Males blue c. & 28.7 & 5.6 & 33.5 & 2.4 & 4.7 & 2.4 \\
Males white c. & 30.1 & 4.3 & 31.5 & 1.6 & 1.4 & 1.6 \\
Females blue c. & 23.6 & 7.3 & 31.4 & 1.6 & 7.8 & 1.6 \\
Females white c. & 27.1 & 6.5 & 29.0 & 1.1 & 1.9 & 1.1 \\
\hline
\end{tabular}

such transitions are rare. Our data confirms this statement: only a few hundred transitions of this type are observed.

\section{Sample selection}

As common in the literature, we only select workers aged between 50 and 70 when we estimate models explaining transitions into retirement. By applying this sample selection, we include workers born in, say, 1930. Such workers were 55 years-old in 1985, the first year of our sample. Notice that those individuals of the 1930 generation who have a strong taste for leisure might be excluded. They presumably retired before 1985. In order to avoid such (dynamic) self-selection problems, we only select workers born after 193414 Moreover, we remove those workers from the sample who are born after 1941. This selection is necessary in order to compute financial incentives in a proper way. For this computation we need data from the pension file, which contains information on seniority at retirement (cf. section 3). Members of the 1941 cohort are 65 years-old in 2006, the last year considered in the pension file. Since retiring after age 65 is a very rare event, we can still include the generations born before 1942 without incurring self-selection problems. Such problems may instead arise when we include cohorts born after 1941. Take for instance a worker born in 1950. The seniority of such a person is only observed if he/she retires before the year 2007, i.e. before age 57. By including the 1950 generation, we would self-select those who are more work-averse. To summarize, we select workers born between 1935 and 1941.

\footnotetext{
${ }^{14}$ We implicitly assume that it is impossible to retire before the age of 50. Given the institutional framework described in section 2 this assumption is rather plausible (cf. table 1 .
} 
As said before, workers whose careers have been characterized by long interruptions or contributions mainly to other pension schemes (e.g. in the public or in the agricultural sector) are also automatically excluded, because their seniority is unknown 15

In our study we focus on retirement choices of private sector employees. Retirement behavior of the self-employed are not studied because their earnings are measured with considerable error. We define an employee as retired if he/she permanently leaves the O1M archive and does not afterward work either as an artisan, a trader, or an atypical worker. Notice that employees might have left permanently the O1M archive because they took a job in the public or agricultural sector. Since such labor transitions are rare for people aged 50 or older, we think that we measure the retirement status rather precisely.

Since we focus on voluntary retirement choices, we exclude from the analysis permanent transitions out of the O1M archive through either disability, unemployment or mobility subsidies $\sqrt{16}$ For reasons explained in section 2 , we exclude pension beneficiaries who work at the same time.

\footnotetext{
${ }^{15}$ Their SSW is totally unknown to us. Their inclusion in the sample would have required strong assumptions on the unobserved part of their working careers which had lead to a very imprecise measure of their financial incentives. Previous studies, which did not have any information on pension payments, have selected workers on the basis of an arbitrary minimum number of years in the O1M sample.

${ }^{16}$ In section 2 we already explained that from 1984 onwards transitions into disability are involuntary. The data revealed that a non negligible percentage (6 percent) of the transitions to retirement occurred indirectly through an episode of mobility, and 2 percent through an episode of (paid) unemployment.
} 


\section{$5 \quad$ Financial incentives}

\subsection{Definition}

We define the SSW ${ }^{17}$ for a worker of age $a$ who evaluates retirement at age $h(h \geq a)$ as ${ }^{18}$

$$
S S W_{a, h}= \begin{cases}\sum_{s=h+1}^{\Omega} \rho(s) B_{h}(s) & \text { if } h=a \\ \sum_{s=h+1}^{\Omega} \rho(s) B_{h}(s)-\sum_{s=a+1}^{h} \rho^{\prime}(s) c(s) & \text { if } h>a\end{cases}
$$

where $\Omega$ denotes the life span, $B(s)$ the pension benefit received at age $s$, $c(s)$ the contributions paid at age $s, \rho(s)$ the discount factor at age $s$ which includes a real interest rate and conditional survival probabilities. $\rho(s)$ also accounts for survivors benefits (see appendix A.1 for more details). $\rho /(s)$ is a discount factor which differs from $\rho(s)$ because it does not account for survivors benefits 19

In the empirical part we only consider the following measures of marginal incentives (MI) to retire: the accrual and the peak value (?). These two measures are defined as:

$$
\begin{aligned}
A C C_{a} & =S S W_{a, a+1}-S S W_{a, a} \\
P V_{a} & =\max \left(S S W_{a, h}-S S W_{a, a}\right) \quad h=a+1, \ldots, R
\end{aligned}
$$

where $R$ is the maximum retirement age, fixed to 70 . In the peak value the worker is assumed to be more forward-looking than in the accrual, because

\footnotetext{
${ }^{17}$ See e.g. ? and ?.

${ }^{18} \mathrm{We}$ also account for other kind of benefits (survivor pensions, self-employment pensions and disability checks) in the computation of SSW (see appendix A.1 for more details). However, they are accounted for only if they have been actually received by the employees in the sample. Notice that in this way we do not treat them as alternative exit routes to retirement, but rather as additional income. Quantitatively, their role is marginal, accounting for 1.8 percent of total SSW.

${ }^{19}$ In equation $(1)$, we include both the contributions paid by the employee and by the employer, under the assumption that the latter is actually borne by the employee in the form of lower wages (?). This is also the approach followed by most of the country studies in ?. Accounting for contributions into the computation of SSW and MI affects their values. However, in our case it does not have a noticeable impact on the model estimates. Contributions are in fact proportional to wages and their rate is homogeneous within the population.
} 
more than one possible future retirement age is compared with the current one.

We also experimented with other MI measures, namely the implicit tax rate and the option value (see ?). Empirical results do not seem to be affected by the choice of other MI measures 20

\subsection{Computation}

The computation of financial incentives incorporates worker's (expected) wages and depends on the current and the expected features of the social security system (cf. $B(s)$ and $c(s)$ in equation 1). We model the wage process as follows:

$$
\begin{aligned}
& y_{i t}=\sum_{j=2}^{A} \beta_{j} \text { dage }(j)_{i t}+\sum_{\tau=1}^{T} \gamma_{\tau} \text { dyear }(\tau)_{i t}+c_{i}+u_{i t} \\
& u_{i t}=\varrho u_{i t-1}+\epsilon_{i t} \quad \epsilon_{i t} \sim i i d\left(0, \sigma_{\epsilon}^{2}\right)
\end{aligned}
$$

where index $i$ indicates the worker and $t$ the year. The variable $y_{(.)}$denotes the logarithm of annualized wages, dage $(j)$ and dyear $(\tau)$ a full set of age and time dummies. Notice that model (4) is not identified because of the identity calendar year $=$ year of birth + age (the variable year of birth is subsumed in the fixed effect $c_{i}$ ). Like ? we resolve this identification problem by imposing the two following restrictions on the time dummy coefficients: 1) they add up to zero; 2) they are orthogonal to a time trend. We estimate equation (4) separately by gender and occupation (white collar versus blue collar) by means of the within estimation method. After having estimated equation (4), we compute the residuals $\hat{u}_{i t}$ and $\hat{u}_{i t-1}$ and estimate equation (5). The estimate of $\varrho$ is used in the prediction of future wages (see the appendix A.2 for further details). Model (4)-(5) is also exploited to backcast wages, whenever pensionable earnings are not fully observed (hence especially in the first years of the data).

To compute $B($.$) we follow the rules established for old-age and senior-$ ity pensions in the FPLD scheme. We assume that individuals know the pension formulae and hold static expectations. That is, they plan their retirement choice as if the current pension legislation will not change in the future. This is a standard assumption in the retirement literature. Additional assumptions and computational details are given in appendix A.1.

\footnotetext{
${ }^{20}$ Details are available from the authors upon request.
} 
Table 4: Financial incentives: descriptive statistics by age and gender

\begin{tabular}{|c|c|c|c|c|c|c|c|}
\hline \multirow[b]{2}{*}{ Age } & \multicolumn{2}{|c|}{ SSW } & \multicolumn{2}{|c|}{ Accrual } & \multicolumn{2}{|c|}{ Peak Value } & \multirow[b]{2}{*}{ Eligible } \\
\hline & median & s.d. & median & s.d. & median & s.d. & \\
\hline & \multicolumn{7}{|c|}{ Males } \\
\hline 50 & 17.6 & 10.1 & .169 & 4.54 & 8.01 & 6.33 & .115 \\
\hline 51 & 19.2 & 11.7 & .184 & 4.37 & 6.33 & 6.23 & .180 \\
\hline 52 & 20.3 & 12.6 & .186 & 4.15 & 4.91 & 5.99 & .205 \\
\hline 53 & 21.2 & 13.3 & .139 & 4.09 & 3.92 & 5.89 & .241 \\
\hline 54 & 22.1 & 13.8 & .068 & 3.84 & 2.91 & 5.65 & .265 \\
\hline 55 & 22.6 & 13.8 & 0 & 3.77 & 2.22 & 5.46 & .265 \\
\hline 56 & 22.5 & 13.6 & -.076 & 4.01 & 1.49 & 5.31 & .272 \\
\hline 57 & 22.5 & 13.3 & -.098 & 3.95 & .868 & 4.82 & .283 \\
\hline 58 & 22.3 & 12.8 & -.130 & 3.44 & .389 & 4.25 & .275 \\
\hline 59 & 21.8 & 12.6 & -.277 & 3.20 & -.017 & 3.90 & .356 \\
\hline 60 & 20.1 & 12.3 & -.199 & 2.99 & -.025 & 3.47 & .282 \\
\hline 61 & 18.4 & 11.5 & -.132 & 2.43 & -.027 & 2.75 & .243 \\
\hline 62 & 18.5 & 9.90 & -.115 & 1.70 & -.051 & 1.97 & .203 \\
\hline 63 & 18.2 & 9.55 & -.137 & 1.34 & -.102 & 1.64 & .327 \\
\hline 64 & 17.9 & 9.05 & -.224 & 1.64 & -.192 & 1.77 & .396 \\
\hline 65 & 18.2 & 6.60 & -1.33 & .613 & -1.33 & .681 & .985 \\
\hline \multicolumn{8}{|l|}{$\ldots$} \\
\hline & \multicolumn{7}{|c|}{ Females } \\
\hline 50 & 17.9 & 11.8 & .349 & 2.77 & 2.83 & 3.75 & .079 \\
\hline 51 & 18.9 & 12.4 & .377 & 2.44 & 2.11 & 3.46 & .112 \\
\hline 52 & 18.8 & 12.5 & .384 & 2.35 & 1.55 & 3.42 & .103 \\
\hline 53 & 19.1 & 12.8 & .379 & 2.50 & 1.07 & 3.35 & .124 \\
\hline 54 & 19.2 & 13.0 & .340 & 2.36 & .618 & 3.16 & .109 \\
\hline 55 & 19.2 & 12.9 & -.394 & 2.07 & -.302 & 3.14 & .560 \\
\hline 56 & 18.7 & 14.0 & -.299 & 2.66 & -.177 & 3.41 & .455 \\
\hline 57 & 19.0 & 13.7 & -.430 & 2.15 & -.303 & 3.13 & .486 \\
\hline 58 & 19.7 & 13.8 & -.475 & 2.30 & -.290 & 3.12 & .529 \\
\hline 59 & 20.0 & 13.9 & -.746 & 2.45 & -.746 & 3.06 & .624 \\
\hline 60 & 20.0 & 13.2 & -1.01 & 2.24 & -1.01 & 3.10 & .876 \\
\hline 61 & 18.2 & 14.3 & -.869 & 3.26 & -.869 & 3.81 & .813 \\
\hline
\end{tabular}

Notes: monetary values are in $10.000 €$, prices 2006. The column Eligible indicates the quota of workers of that age and gender who is eligible for either the old-age or the seniority pension. 
Descriptive statistics for financial incentives are provided in table 4. Like previous studies, we find that the pension rules provide a strong marginal incentive to retire at minimum requirement. As more and more workers become eligible, the median accrual and peak value eventually decrease and become negative.

\section{The retirement model}

We consider the following latent variable retirement model for worker $i$ in period $t(t=1, \ldots, T)$

$$
y_{i t}^{*}=\mathbf{w}_{i t}^{\prime} \boldsymbol{\theta}+c_{i}+\epsilon_{i t}
$$

where we observe

$$
\begin{array}{lll}
y_{i t}=1 & \text { if } y_{i, t}^{*}>0 & \text { (retires) } \\
y_{i t}=0 & \text { otherwise } &
\end{array}
$$

and, due to the absorbing state assumption, $y_{i t}=1$ implies $y_{i 1}=y_{i 2}=$ $\ldots y_{i t-1}=0$. We then define

$$
\mathbf{w}_{i t}^{\prime} \boldsymbol{\theta}=S S W_{i t} \beta_{1}+M I_{i t} \beta_{2}+\mathbf{x}_{i t}^{1 \prime} \boldsymbol{\delta}_{\mathbf{1}}+\mathbf{x}_{i}^{2 \prime} \boldsymbol{\delta}_{\mathbf{2}}
$$

where $S S W_{i t}$ is equal to $S S W_{a, a}$ as in equation (1) for worker $i$ aged $a$ in year $t$. $M I_{i t}$ is given either by $A C C_{i t}$ or $P V_{i t}$, according to the specification. Obviously, $A C C_{i t}$ and $P V_{i t}$ are equal to $A C C_{a}$ and $P V_{a}$ for worker $i$ aged $a$ in year $t . \mathbf{x}_{i t}^{1}$ and $\mathbf{x}_{i}^{2}$ are vectors of time-varying and time-constant variables. The former includes age, expected and current wage, pensionable earnings, occupation, sector and year dummies, whereas the latter contains cohort and area of birth dummies ${ }^{21} \beta_{1}$ and $\beta_{2}$ are the key parameters to be estimated, expected to be positive and negative respectively.

Concerning the idiosyncratic error term $\epsilon_{i t}$, we make the following standard assumption

$$
\epsilon_{i t} \mid \mathbf{w}_{i t} \boldsymbol{\theta}, c_{i} \sim N I D(0,1)
$$

Notice that equation (6) contains an individual effect $c_{i}$. This effect captures unobserved differences across individuals in e.g. taste for work. The individual effects and financial incentive variables can be correlated. For example,

\footnotetext{
${ }^{21}$ We get rid of the perfect collinearity trap between age, cohort and year by applying the same restriction on the year dummies as in the wage model, see ?.
} 
a work-loving individual may tend to have high SSW and low retirement probability. We use the methodology of ? in order to take into account these correlations: we include as extra regressors financial incentives in the first year each worker is observed. In other words, we model the individual effect as follows:

$$
c_{i}=\mathbf{z}_{i 1}^{\prime} \gamma+\alpha_{i} \quad c_{i} \mid \mathbf{w}_{i t}, \boldsymbol{\theta} \sim N I D\left(\mathbf{z}_{i 1}^{\prime} \gamma, \sigma_{\alpha}^{2}\right)
$$

where $\mathbf{z}_{i 1} \equiv\left(S S W_{i 1}, M I_{i 1}, \mathbf{x}_{i 1}^{1}\right)^{\prime}$. Given our focus on financial incentives, however, we only include in $\mathbf{x}_{i 1}^{1}$ current and expected wages. Although $\gamma$ measures the correlation between financial incentives and the individual unobserved effect, no clear economic interpretations can be given to their estimates.

The likelihood contribution of individual $i$ who retires in period $\mathrm{T}$ is as follows ${ }^{22}$

$$
\begin{aligned}
\mathscr{L}_{i}\left(\boldsymbol{\theta}, \boldsymbol{\gamma} \mid \mathbf{y}_{i}, \mathbf{w}_{i}, \mathbf{z}_{i 1}, \alpha_{i}\right) & =\left[\prod_{t=1}^{T-1} \Phi\left(-\mathbf{w}_{i t}^{\prime} \boldsymbol{\theta}-\mathbf{z}_{i 1}^{\prime} \boldsymbol{\gamma}-\alpha_{i}\right)\right] \Phi\left(\mathbf{w}_{i T} \boldsymbol{\theta}+\mathbf{z}_{i 1}^{\prime} \boldsymbol{\gamma}+\alpha_{i}\right) \\
& =\left[\prod_{t=1}^{T} \Phi\left[\left(2 y_{i t}-1\right)\left(\mathbf{w}_{i t}^{\prime} \boldsymbol{\theta}+\mathbf{z}_{i 1}^{\prime} \boldsymbol{\gamma}+\alpha_{i}\right)\right]\right]
\end{aligned}
$$

where $\mathbf{y}_{i} \equiv\left(y_{i 1}, \ldots, y_{i T}\right)^{\prime}, \mathbf{w}_{i} \equiv\left(\mathbf{w}_{i 1}, \ldots, \mathbf{w}_{i T}\right)^{\prime}, \Phi($.$) is the standard normal$ c.d.f.

$\alpha_{i}$ is then integrated out by computing 23

$\mathscr{L}_{i}\left(\boldsymbol{\theta}, \boldsymbol{\gamma} \mid \mathbf{y}_{i}, \mathbf{w}_{i}, \mathbf{z}_{i 1}\right)=\frac{1}{\sigma_{\alpha}} \int_{-\infty}^{\infty}\left[\prod_{t=1}^{T} \Phi\left[\left(2 y_{i t}-1\right)\left(\mathbf{w}_{i t}^{\prime} \boldsymbol{\theta}+\mathbf{z}_{i 1}^{\prime} \boldsymbol{\gamma}+\alpha_{i}\right)\right]\right] \phi\left(\frac{\alpha_{i}}{\sigma_{\alpha}}\right) d \alpha_{i}$

where $\phi($.$) is the standard normal density. The model is estimated separately$ for males and females.

\section{Results}

Results are shown in table 5 and 6 for males and females respectively. We present four (rather standard) alternative specifications, where MI are measured either by the accrual or by the peak value and where age is either

\footnotetext{
${ }^{22}$ In our sample we selected employees who were 50 in the first wave. This implies that for people who retire at age $51, T=1$. In our sample, the retirement date $T$ could take on the values 1 (age 51) until 20 (age 70).

${ }^{23}$ We maximize this likelihood by the xtprobit Stata routine.
} 
modeled as a linear function (columns $a$ ) or as a linear function plus a dummy at age 65 for males or 55 for females (columns $b$ ). In the tables we report marginal effects for a change in the monetary variables of 10 thousand $€$, and for a change from 0 to 1 in the age dummies ${ }^{24}$

Financial incentives are found to affect retirement choices in the expected way: the higher the SSW, the higher the probability to retire ${ }^{25}$ the higher the accrual or the peak value, the lower the probability to retire. As indicated by specification $A C C$ - $b$ in table 5 , for example, the probability for a male to retire increases by 0.4 percentage points if SSW increases by 10 thousand $€$ (its sample mean is 230 thousand $€$ ) and decreases by 1.7 percentage points if ACC increases by the same amount. Females react stronger to financial incentives than males. For example, an increase in the ACC of 10 thousand $€$ reduces their probability to retire by 4.2 percentage points. Parameter values are found robust across age specifications, and very precisely estimated (at 1 percent significance level).

In order to quantify the impact on retirement of financial incentives, we perform two simulations. They are similar to those illustrated in ? ${ }^{26}$ The first one assumes that eligibility requirements increase from the values illustrated in table 1 to their steady-state values, i.e. to the values shown in the last row of the same table. This results in an average increase in the minimum requirements by 3 years. The second simulation depicts a more actuarially neutral pension formula. It considers a reduction in the pension benefit of 6 percent for each retirement age before age 65 (60 for females) and an increase of the same amount for retirement after that age. Results show a large impact of the policy changes on retirement. In the first simulation the average retirement age increases in fact by 2 years, while in the second by 5 years $(2$ years for females) 27 .

\footnotetext{
${ }^{24}$ We have also considered alternative specifications for age and wage expectations. The first one includes a complete set of age dummies (this specification is used to select appropriate age dummies for specifications $b$ ). In the second specification it is assumed that expected future wages are equal to current wage. In the third specification, expected future wages are predicted using a dynamic model. Results turned out to be very robust to the alterative specifications.

${ }^{25}$ The exceptions to this general finding are the specifications for females with PV as the MI measure. In these specifications the estimate of the SSW coefficient has a negative sign. However, those estimates do not differ significantly from zero at the 1 percent level.

${ }^{26}$ Simulations are based on specifications $b$. Results are found similar for the specifications with the ACC and with the PV.

${ }^{27}$ At early retirement ages, due to the pension cut, the pension becomes lower than
} 
Table 5: Random effects estimates for retirement: males, marginal effects

\begin{tabular}{|c|c|c|c|c|}
\hline \multirow[b]{2}{*}{ COEFF. } & \multicolumn{2}{|c|}{ Accrual $(A C C)$} & \multicolumn{2}{|c|}{ Peak Value $(P V)$} \\
\hline & (a) & (b) & (a) & (b) \\
\hline \multirow[t]{2}{*}{$S S W$} & $0.0041^{* * *}$ & $0.0042^{* * *}$ & $0.0011^{* * *}$ & $0.0012^{* * *}$ \\
\hline & $(0.0002)$ & $(0.0002)$ & $(0.0002)$ & $(0.0002)$ \\
\hline \multirow[t]{2}{*}{$M I$} & $-0.0167 * * *$ & $-0.0166^{* * *}$ & $-0.0099 * * *$ & $-0.0099 * * *$ \\
\hline & $(0.0006)$ & $(0.0006)$ & $(0.0004)$ & $(0.0004)$ \\
\hline \multirow[t]{2}{*}{ age } & $0.0095^{* * *}$ & $0.0094^{* * *}$ & $0.0059^{* * *}$ & $0.0058 * * *$ \\
\hline & $(0.001)$ & $(0.001)$ & $(0.0009)$ & $(0.0009)$ \\
\hline \multirow[t]{2}{*}{ age65 } & & $0.186^{* * *}$ & & $0.188^{* * *}$ \\
\hline & & $(0.053)$ & & $(0.052)$ \\
\hline \multirow[t]{2}{*}{$S S W_{1}$} & $-0.00059^{* * *}$ & $-0.00063^{* * *}$ & $0.00087^{* * *}$ & $0.00078^{* * *}$ \\
\hline & $(0.0001)$ & $(0.0001)$ & $(0.0002)$ & $(0.0002)$ \\
\hline \multirow[t]{2}{*}{$M I_{1}$} & $0.00037^{*}$ & $0.00034^{*}$ & $0.00145^{* * *}$ & $0.00136^{* * *}$ \\
\hline & $(0.0002)$ & $(0.0002)$ & $(0.0002)$ & $(0.0002)$ \\
\hline Nb Obs. & 39007 & 39007 & 39007 & 39007 \\
\hline $\mathrm{Nb}$ Ind. & 6040 & 6040 & 6040 & 6040 \\
\hline Log-lik & -9663 & -9643 & -9511 & -9488 \\
\hline Pseudo-R2 & 0.319 & 0.320 & 0.330 & 0.331 \\
\hline \multirow[t]{2}{*}{$\sigma_{\alpha}$} & $0.189^{* * *}$ & $0.189^{* * *}$ & $0.187^{* * *}$ & $0.188^{* * *}$ \\
\hline & $(0.016)$ & $(0.016)$ & $(0.015)$ & $(0.015)$ \\
\hline \multicolumn{5}{|c|}{ Wald-test of $\mathbf{z}_{i 1}=0^{(a)}$ (p-values in parenthesis): } \\
\hline \multirow[t]{2}{*}{$\chi_{4}^{2}$} & 53.05 & 54.40 & 52.84 & 55.38 \\
\hline & $(0)$ & $(0)$ & $(0)$ & $(0)$ \\
\hline
\end{tabular}

Notes: monetary values are in $10.000 €$, prices 2006 ; ${ }^{* *} p<0.01,{ }^{* *} p<0.05$, ${ }^{*} p<0.1$, s.e. in parenthesis; not reported: expected and current wage, pensionable earnings, expected and current wage in the first year the worker is observed, dummies for occupation, year, cohort, sector, area; ${ }^{(a)} \mathbf{z}_{i 1}$ includes $S S W_{1}, M I_{1}$, expected and current wage in the first year the worker is observed. 
Table 6: Random effects estimates for retirement: females, marginal effects

\begin{tabular}{|c|c|c|c|c|}
\hline \multirow[b]{2}{*}{ COEFF. } & \multicolumn{2}{|c|}{ Accrual $(A C C)$} & \multicolumn{2}{|c|}{ Peak Value $(P V)$} \\
\hline & (a) & (b) & (a) & (b) \\
\hline \multirow[t]{2}{*}{$S S W$} & $0.00623^{* * *}$ & $0.00635^{* * *}$ & $-0.00269 *$ & $-0.00305^{* *}$ \\
\hline & $(0.0010)$ & $(0.0010)$ & $(0.0015)$ & $(0.0015)$ \\
\hline \multirow[t]{2}{*}{$M I$} & $-0.0455^{* * *}$ & $-0.0420 * * *$ & $-0.0374 * * *$ & $-0.0365^{* * *}$ \\
\hline & $(0.0029)$ & $(0.0028)$ & $(0.0021)$ & $(0.0021)$ \\
\hline \multirow[t]{2}{*}{ age } & $0.0506^{* * *}$ & $0.0408^{* * *}$ & $0.0405^{* * *}$ & $0.0343^{* * *}$ \\
\hline & $(0.0051)$ & $(0.0045)$ & $(0.0043)$ & $(0.0042)$ \\
\hline \multirow[t]{2}{*}{ age 55} & & $0.1320^{* * *}$ & & $0.1320^{* * *}$ \\
\hline & & $(0.016)$ & & $(0.015)$ \\
\hline \multirow[t]{2}{*}{$S S W_{1}$} & 0.000908 & 0.000657 & $0.00716^{* * *}$ & $0.00782^{* * *}$ \\
\hline & $(0.0011)$ & $(0.0010)$ & $(0.0016)$ & $(0.0016)$ \\
\hline \multirow[t]{2}{*}{$M I_{1}$} & $0.00421^{* * *}$ & $0.00406^{* * *}$ & $0.00892^{* * *}$ & $0.00983^{* * *}$ \\
\hline & $(0.0016)$ & $(0.0015)$ & $(0.0018)$ & $(0.0018)$ \\
\hline Nb Obs. & 9245 & 9245 & 9245 & 9245 \\
\hline Nb Ind. & 1801 & 1801 & 1801 & 1801 \\
\hline Log-lik & -3229 & -3173 & -3196 & -3136 \\
\hline Pseudo-R2 & 0.225 & 0.238 & 0.233 & 0.247 \\
\hline \multirow[t]{2}{*}{$\sigma_{\alpha}$} & $0.357^{* * *}$ & $0.203^{* * *}$ & $0.209^{* * *}$ & $0.184^{* * *}$ \\
\hline & $(0.095)$ & $(0.059)$ & $(0.067)$ & $(0.029)$ \\
\hline \multicolumn{5}{|c|}{ Wald-test of $\mathbf{z}_{i 1}=0^{(a)}$ (p-values in parenthesis): } \\
\hline \multirow[t]{2}{*}{$\chi_{4}^{2}$} & 7.85 & 8.36 & 30.38 & 33.59 \\
\hline & $(0.0973)$ & $(0.0791)$ & $(0)$ & $(0)$ \\
\hline
\end{tabular}

Notes: monetary values are in $10.000 €$, prices 2006 ; ${ }^{* * *} p<0.01,{ }^{* *} p<0.05$,

$* p<0.1$, s.e. in parenthesis; not reported: expected and current wage, pensionable earnings, expected and current wage in the first year the worker is observed, dummies for occupation, year, cohort, sector, area; ${ }^{(a)} \mathbf{z}_{i 1}$ includes $S S W_{1}, M I_{1}$, expected and current wage in the first year the worker is observed. 
We also measure how the average worker's retirement probability is affected by a change in his financial incentives when he becomes eligible for a pension benefit ${ }^{28}$ Due to the huge changes in his financial incentives which occur at this time - his SSW increases from 250 to 350 thousand $€$, and his ACC reduces from +70 to -13 thousand $€$ - his probability to retire increases by around 30 percentage points. Similar results are obtained for the average female. Females' higher marginal effects are in fact compensated by smaller changes in both her SSW and MI at minimum requirements. For instance, her ACC reduces 'only' from +21 to -9 thousand $€$.

Age is found to be an important determinant of retirement choices: the older the employee, the higher his/her probability to retire. In the case of males, a linear trend seems to fit the data quite well (the pseudo R-squared is satisfactory, above 30 percent). Being 65 further increases males retirement probability by 19 percentage points ${ }^{29}$ However, this spike is quantitatively unimportant because most males retire well before age 65 . For females we find a spike at age 55. Predicted and raw hazard rates by age, for the specifications with the peak value, are shown in figure 1 for males and in figure 2 for females. From figure 2 it can be inferred that financial incentives can explain well smaller humps at ages different from 55 (e.g. at age 60).

Spikes of exits at some typical retirement ages are a common finding in the retirement literature. ? find the existence of two - and not one spikes for males, one at the early retirement age and another one at the normal retirement age, in almost every country 30 For Italy two spikes are also commonly found, one at age 60 and another one at 65 . However, we do not observe a spike at age 60 (see figure 1). It should be realized that in comparison with the previous Italian studies we analyze the retirement of younger cohorts, born after 1935. The spike at age 60 is a typical phe-

the minimum pension and is thus subsidized. As minimum pensions are granted more to females than to males, the policy change affects more the latter than the former group.

${ }^{28}$ In the simulation, we set the dummy variables and the individual effect to zero, and the monetary variables to their sample mean. The simulation is based on specification $A C C$ - $b$ for males.

${ }^{29}$ Age 65 is not a compulsory retirement age (a statutory retirement age does not exist in Italy, although for some work contracts it is fixed at age 70). For almost all the years under analysis, it is even not a minimum requirement for the old-age pension. As already mentioned in section 2 the minimum age for the old-age pension was 60 in the pre-reform period and 65 from 2000 onwards. According to ? (pag. 208) "(...) although retirement is not compulsory, there is virtually no possibility of working beyond age 65 ".

${ }^{30}$ See the illustrative figures at pages $22-27$ of the book. 
Figure 1: Hazard rates by age: males

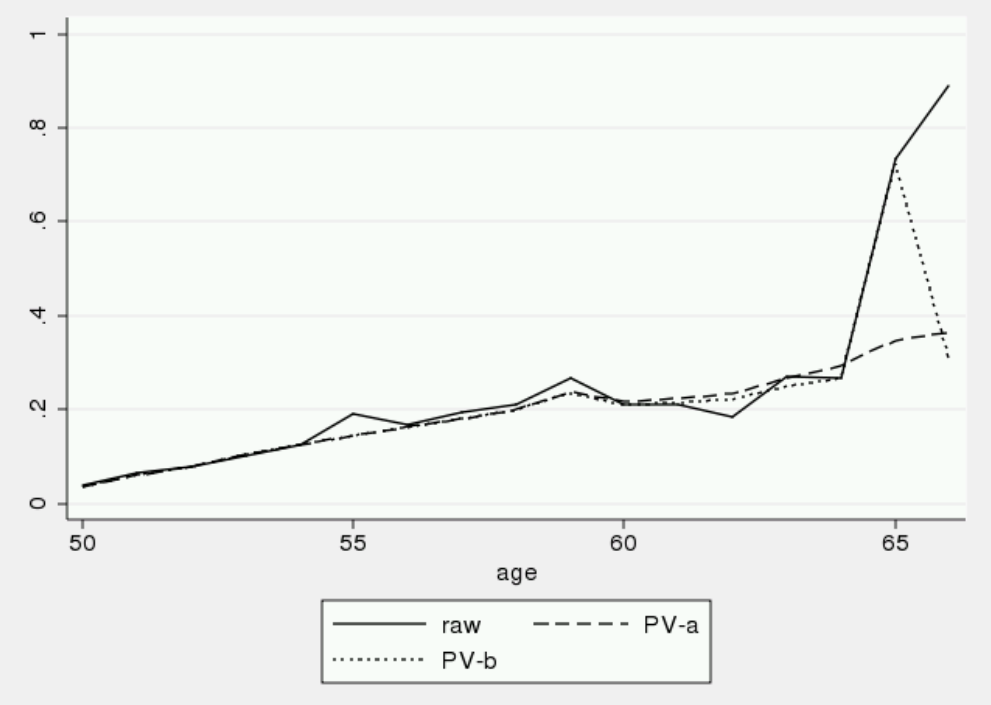

Figure 2: Hazard rates by age: females

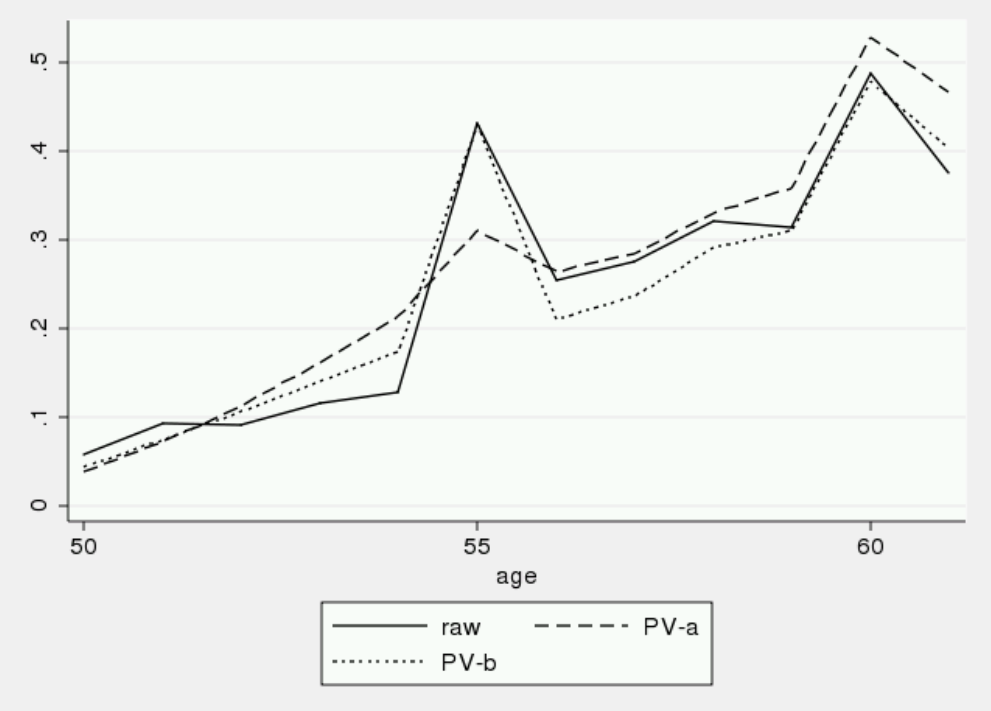


nomenon of the pre-reform period. As a confirmation, the spike is found to re-appear if we include in the sample cohorts born before 1935 .

The point estimates of $\sigma_{\alpha}$ are rather small, but significantly different from zero. Ignoring individual unobserved heterogeneity would lead to inconsistent estimates of the key parameters of the model due to the selfselection problems mentioned in the introduction. The estimation results also indicate that there exists a significant correlation between individual unobserved heterogeneity and the financial incentives: $S S W_{1}$ and $M I_{1}$ and the other time varying variables seem to be jointly significant (cf. the Wald tests present at the bottom of tables 5 and 6 .

In order to check whether and how much our findings depend on the availability of precise information on seniority, we finally re-estimate the model after replacing SSW and MI measures as computed by us with the same variables computed according to the imputation methodology used in previous studies. Table 7 shows the results. It indicates a strong reduction of the effect of MI on retirement, and a significantly negative estimate for the SSW coefficient. The fit to the data is also much worse. Interestingly, results in table 7 look qualitatively similar to those in ?, which show a negative, albeit insignificant estimates for SSW in the majority of the specifications.

\section{Conclusions}

Our study exploits a new dataset in order to quantify the effect of financial incentives on retirement choices. This dataset contains - for the first time in Italy - information on seniority. Our econometric methodology takes into account correlated unobserved heterogeneity. Variability for financial incentives is provided by a series of reforms, which heavily affected both the access and the amount of social security benefits in Italy in the '90s.

In accordance with the general finding in ?, we find that financial incentives have an effect on retirement. The effect goes in the expected direction; when employees become eligible for pension benefits the change in financial incentives they experience is so high that their retirement probability increases in a sizable way.

We also find that the procedure to impute seniority used in previous studies leads to a sizable measurement error. Due to this measurement error, the key parameters of the model are inconsistently estimated. Our 
Table 7: Random effects estimates for retirement when seniority is computed as in previous studies: marginal effects

\begin{tabular}{lcccc}
\hline \multicolumn{3}{c}{ Males } & \multicolumn{2}{c}{ Females } \\
COEFF. & $A C C$ & $P V$ & $A C C$ & $P V$ \\
\hline$S S W$ & $-0.00146^{* * *}$ & $-0.00664^{* * *}$ & $-0.00938^{* * *}$ & $-0.0146^{* * *}$ \\
& $(0.00032)$ & $(0.00072)$ & $(0.0016)$ & $(0.0020)$ \\
$M I$ & $-0.00408^{* * *}$ & $-0.00785^{* * *}$ & $-0.0287^{* * *}$ & $-0.0249^{* * *}$ \\
& $(0.00048)$ & $(0.00082)$ & $(0.0035)$ & $(0.0032)$ \\
age & $0.0216^{* * *}$ & $0.0187^{* * *}$ & $0.0503^{* * *}$ & $0.0442^{* * *}$ \\
& $(0.0024)$ & $(0.0024)$ & $(0.0057)$ & $(0.0054)$ \\
age65 & $0.380^{* * *}$ & $0.368^{* * *}$ & & \\
& $(0.074)$ & $(0.074)$ & & $0.171^{* * *}$ \\
age55 & & & $0.174^{* * *}$ & $(0.018)$ \\
& & & $(0.018)$ & 8684 \\
Nb Obs. & 37202 & 37202 & 8684 & 1710 \\
Nb Ind. & 5738 & 5738 & 1710 & -3274 \\
Log-lik & -11806 & -11786 & -3267 & 0.167 \\
Pseudo-R2 & 0.123 & 0.124 & 0.168 & \\
\hline
\end{tabular}

Notes: monetary values are in $10.000 €$, prices 2006 ; $^{* * *} p<0.01,{ }^{* *} p<0.05$, $* p<0.1$, s.e. in parenthesis; not reported: expected and current wage, pensionable earnings, $\mathbf{z}_{i 1}$ variables, dummies for occupation, year, cohort, sector, area.

sensitivity analysis suggests that the lack of appropriate information on seniority is an important reason for the unclear evidence so far obtained in retirement studies for Italy. 


\section{A SSW computation}

\section{A.1 Formulae and additional assumptions}

Total SSW is given by

$$
T S S W_{a, h}=S S W_{a, h}+S S W_{a, h}^{\text {sur }}+S S W_{a, h}^{i n v}+S S W_{a, h}^{s e}
$$

where

$$
\begin{aligned}
S S W_{a, h} & = \begin{cases}\sum_{s=h+1}^{\Omega} \rho(s) B_{h}(s) & \text { if } h=a \\
\sum_{s=h+1}^{\Omega} \rho(s) B_{h}(s)-\sum_{s=a+1}^{h} \rho^{\prime}(s) c(s) & \text { if } h>a\end{cases} \\
S S W_{a, h}^{\text {sur }} & =\bar{B}^{\text {sur }} \sum_{s=a+1}^{\Omega} \rho^{\prime}(s) \\
S S W_{a, h}^{\text {inv }} & =\bar{B}^{\text {inv }} \sum_{s=a+1}^{\text {agemr }(\mathrm{h})} \rho^{\prime}(s) \\
S S W_{a, h}^{\text {se }} & =\bar{B}^{\text {se }} \sum_{s=\text { agese }}^{\Omega} \rho(s)
\end{aligned}
$$

and

$$
\begin{aligned}
& \rho(s)=\beta^{s-a} \pi(s \mid a)\left[1+\lambda 0.6 \beta q_{s+1} \sum_{\tau=s+1}^{\Omega} \pi(\tau-\epsilon \mid s+1-\epsilon) \beta^{\tau-s-1}\right](17) \\
& \rho^{\prime}(s)=\beta^{s-a} \pi(s \mid a) \\
& c(s)=\eta Y_{s} \\
& \lambda= \begin{cases}1 & \text { if } \bar{B}^{\text {sur }}=0 \\
0 & \text { otherwise }\end{cases} \\
& B_{h}(s)= \begin{cases}B_{h}(h) \cdot(1+\eta g)^{s-h} & \text { if } \mathrm{s} \geq \operatorname{agemr}(\mathrm{h}) \\
0 & \text { otherwise }\end{cases} \\
& B_{h}(h)= \begin{cases}P E \cdot \alpha \cdot \min \left(\operatorname{sen}_{h}, 40\right) & \text { if year }<1993 \\
P E \cdot \alpha \cdot \operatorname{sen}_{92}+ & \\
P E^{\prime} \cdot \alpha^{\prime} \cdot\left[\min \left(\operatorname{sen}_{h}, 40\right)-\operatorname{sen}_{92}\right] & \text { if year } 1993-1995 \\
P E \cdot \alpha \cdot \operatorname{sen}_{92}+ & \\
P E^{\prime \prime} \cdot \alpha^{\prime} \cdot\left[\min \left(\operatorname{sen}_{h}, 40\right)-\operatorname{sen}_{92}\right] & \text { if year }>1995\end{cases}
\end{aligned}
$$




$$
\begin{gathered}
P E=\frac{\sum_{x=0}^{4} Y_{h-x}}{5} \\
P E^{\prime}=\frac{\sum_{x=0}^{k} Y_{h-x}(1+0.01 x)}{k} \\
P E^{\prime \prime}=\frac{\sum_{x=0}^{k^{\prime}} Y_{h-x}(1+0.01 x)}{k^{\prime}} \\
\alpha= \begin{cases}0.02 & P E \leq \theta_{1} \\
0.015 & \theta_{1}<P E \leq \theta_{2} \\
0.0125 & \theta_{2}<P E \leq \theta_{3} \\
0.01 & P E>\theta_{3}\end{cases} \\
\alpha^{\prime}= \begin{cases}0.02 & P E^{\prime} \leq \theta_{1} \\
0.016 & \theta_{1}<P E^{\prime} \leq \theta_{2} \\
0.0135 & \theta_{2}<P E^{\prime} \leq \theta_{3} \\
0.011 & \theta_{3}<P E^{\prime} \leq \theta_{4} \\
0.009 & P E>\theta_{4}\end{cases} \\
\theta_{2}=1.33 \theta_{1}, \theta_{3}=1.66 \theta_{1}, \theta_{4}=1.9 \theta_{1}
\end{gathered}
$$

The progressive increase in the number of years included in the computation of pensionable earnings established by the reforms $\left(k\right.$ and $\left.k^{\prime}\right)$ is shown in table 8. The increase in minimum requirements for old-age and seniority pensions (agemr) is instead highlighted in table 1 of the main text.

Table 8: Number of years included in the computation of $P E^{\prime}$ and $P E^{\prime \prime}$

\begin{tabular}{lcc}
\hline retirement year & $k$ & $k^{\prime}$ \\
\hline 1993 & 5 & $\cdot$ \\
1994 & 6 & $\cdot$ \\
1995 & 6 & $\cdot$ \\
1996 & 7 & 7 \\
1997 & 7 & 8 \\
1998 & 8 & 8 \\
1999 & 8 & 9 \\
2000 & 9 & 10 \\
2001 & 9 & 10 \\
$>2001$ & 10 & 10 \\
\hline
\end{tabular}

Additional assumptions for SSW computation are listed below and in table 9, where we also exhibit symbols. 
Table 9: SSW: symbols

\begin{tabular}{|lll|}
\hline Symbol & Meaning & Values \\
\hline$a$ & age & \\
$\beta$ & retirement age & 0.97 (discount rate 3 percent) \\
$\pi$ & financial discount factor & ISTAT 1990, by age and gender \\
$q$ & conditional survival probability & ISTAT 1990, by age and gender \\
$\epsilon$ & mortality rate & 3 if male, -3 if female \\
$\eta$ & age difference between spouses & fixed by law \\
$\bar{B}^{\text {sur }}$ & payroll tax rate & observed in the data \\
$\bar{B}^{\text {inv }}$ & survivors benefit & observed in the data \\
$\bar{B}^{\text {se }}$ & invalidity check & observed in the data \\
$g$ & wages rate of growth & historical values \\
$\eta$ & wages indexation & 1 up to 1992, 0 afterward \\
agemr & age at which eligibility is reached & \\
agese & age at which the self-empl. p. is paid & \\
$Y$ & annualized wage & constant prices, 2006 $€$ \\
sen $_{h}$ & accrued seniority at retirement & \\
$\operatorname{sen}_{92}$ & accrued seniority at the end of 1992 & \\
$\theta_{1}$ & first threshold for PE return & fixed by law \\
\hline
\end{tabular}

- financial flows are gross of personal income taxes;

- TFR fund is not accounted for (see ?);

- survivor benefits: workers are married. Husbands are 3 years older than their spouses $(\epsilon=3)$. The pension is paid only to the widow(er), and is equal to 60 percent of the donor's pension. 


\section{A.2 Modeling wages}

We estimate equation (4) on a sub-sample of WHIP data which includes fulltime employees aged 40 to 59 (54 for females). Workers younger than 40 are excluded because our sample of workers at risk of retirement includes workers aged 50 or older, and pensionable earnings are computed on a maximum of past 10 years of wages. Workers older than 59 (54 for females) are excluded because they do not represent a random sample: only those with lower wages remain in the labor market above the minimum old-age age requirements (i.e. age 60 and 55 in the pre-reform period). After that age, we assume a constant wage profile.

Wages have been annualized, i.e. transformed in annual wages if the individual has worked for less than 52 weeks during the year. Fixed effects estimates are shown in table 10 . The corresponding average age-wage profiles are shown in figure 3

Figure 3: Age-wage profiles, by gender and occupation

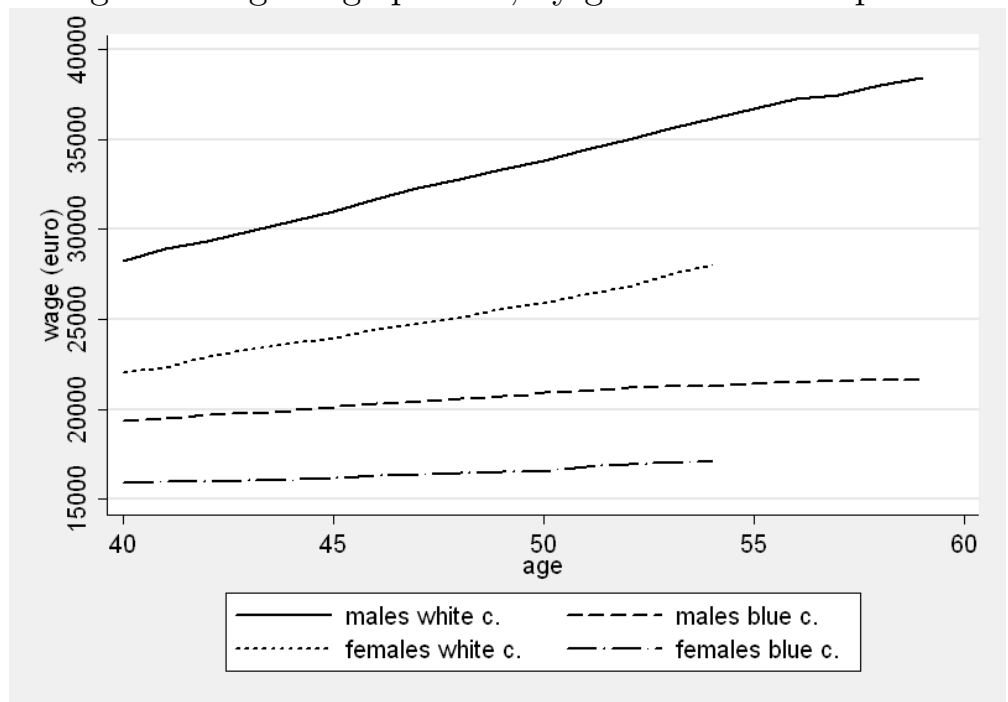

Future wages are forecasted as follows:

$$
E_{t}\left[y_{i t+k}\right]=y_{i t} \cdot \exp \left[\left(\hat{\beta}_{t+k}-\hat{\beta}_{t}\right)+\left(\hat{\varrho}^{k}-1\right) \hat{u}_{i t}\right], \quad k=0,1, \ldots
$$


Table 10: Fixed effects estimates for log-wages, by gender and occupation

\begin{tabular}{|c|c|c|c|c|}
\hline \multirow[b]{2}{*}{ COEFF. } & \multicolumn{2}{|c|}{ Males } & \multicolumn{2}{|c|}{ Females } \\
\hline & Blue c. & White c. & Blue c. & White c. \\
\hline dage41 & $0.0079^{* *}$ & $0.0237^{* * *}$ & 0.0028 & $0.0137^{*}$ \\
\hline dage42 & $0.0190 * * *$ & $0.0370 * * *$ & 0.0027 & $0.0399 * * *$ \\
\hline dage 43 & $0.0238^{* * *}$ & $0.0564^{* * *}$ & 0.0074 & $0.0575^{* * *}$ \\
\hline dage44 & $0.0305^{* * *}$ & $0.0743^{* * *}$ & $0.0102^{*}$ & $0.0713^{* * *}$ \\
\hline dage 45 & $0.0408^{* * *}$ & $0.0919 * * *$ & $0.0164^{* * *}$ & $0.0837^{* * *}$ \\
\hline dage46 & $0.0486^{* * *}$ & $0.1142^{* * *}$ & $0.0246^{* * *}$ & $0.1038^{* * *}$ \\
\hline dage 47 & $0.0545^{* * *}$ & $0.1338^{* * *}$ & $0.0300^{* * *}$ & $0.1168^{* * *}$ \\
\hline dage 48 & $0.0624^{* * *}$ & $0.1494^{* * *}$ & $0.0334^{* * *}$ & $0.1297^{* * *}$ \\
\hline dage49 & $0.0691^{* * *}$ & $0.1664^{* * *}$ & $0.0379 * * *$ & $0.1496^{* * *}$ \\
\hline dage50 & $0.0788^{* * *}$ & $0.1807 * * *$ & $0.0400^{* * *}$ & $0.1624^{* * *}$ \\
\hline dage 51 & $0.0846^{* * *}$ & $0.1983^{* * *}$ & $0.0549^{* * *}$ & $0.1805^{* * *}$ \\
\hline dage52 & $0.0917 * * *$ & $0.2127^{* * *}$ & $0.0621^{* * *}$ & $0.1962^{* * *}$ \\
\hline dage 53 & $0.0963^{* * *}$ & $0.2310^{* * *}$ & $0.0682^{* * *}$ & $0.2217^{* * *}$ \\
\hline dage 54 & $0.0979 * * *$ & $0.2466^{* * *}$ & $0.0708^{* * *}$ & $0.2405^{* * *}$ \\
\hline dage 55 & $0.1035^{* * *}$ & $0.2610^{* * *}$ & & \\
\hline dage56 & $0.1068^{* * *}$ & $0.2772^{* * *}$ & & \\
\hline dage 57 & $0.1093^{* * *}$ & $0.2817^{* * *}$ & & \\
\hline dage 58 & $0.1124^{* * *}$ & $0.2963^{* * *}$ & & \\
\hline dage59 & $0.1125^{* * *}$ & $0.3083^{* * *}$ & & \\
\hline dpyyy 3 & $-0.0204^{* * *}$ & $-0.0086^{* * *}$ & $-0.0095 * * *$ & -0.0037 \\
\hline dpyyy 4 & -0.0003 & $0.0095^{* * *}$ & 0.0032 & 0.0006 \\
\hline dpyyy 5 & $0.0132^{* * *}$ & $0.0112^{* * *}$ & $0.0174^{* * *}$ & $0.0085^{* *}$ \\
\hline dpyyy 6 & $0.0217^{* * *}$ & $0.0247^{* * *}$ & $0.0122^{* * *}$ & $0.0108^{* * *}$ \\
\hline dpyyy 7 & $0.0485^{* * *}$ & $0.0522^{* * *}$ & $0.0350^{* * *}$ & $0.0501^{* * *}$ \\
\hline dpyyy 8 & $0.0409^{* * *}$ & $0.0491^{* * *}$ & $0.0331^{* * *}$ & $0.0418^{* * *}$ \\
\hline dpyyy 9 & $0.0204^{* * *}$ & $0.0261^{* * *}$ & $0.0132^{* * *}$ & $0.0329 * * *$ \\
\hline dpyyy 10 & $0.0130^{* * *}$ & $0.0100 * * *$ & $0.0063^{*}$ & $0.0108^{* *}$ \\
\hline dpyyy11 & $0.0057^{* * *}$ & $0.0091^{* * *}$ & $-0.0078^{* *}$ & -0.0005 \\
\hline dpyyy 12 & 0.0002 & -0.0036 & $-0.0158^{* * *}$ & $-0.0106^{* *}$ \\
\hline dpyyy 13 & $0.0227^{* * *}$ & $0.0074^{* *}$ & 0.0059 & $-0.0115^{* *}$ \\
\hline dpyyy 14 & $0.0091^{* * *}$ & -0.0038 & -0.0074 & $-0.0126^{* *}$ \\
\hline dpyyy 15 & $0.0217^{* * *}$ & $0.0125^{* * *}$ & 0.0056 & -0.0018 \\
\hline dpyyy 16 & $-0.0230^{* * *}$ & $-0.0262^{* * *}$ & $-0.0136^{* *}$ & $-0.0172^{* *}$ \\
\hline dpyyy 17 & $-0.0226^{* * *}$ & $-0.0221^{* * *}$ & -0.0045 & $-0.0137^{*}$ \\
\hline dpyyy 18 & $-0.0575^{* * *}$ & $-0.0352^{* * *}$ & -0.0128 & -0.0039 \\
\hline Constant & $9.8696^{* * *}$ & $10.2488^{* * *}$ & $9.6758^{* * *}$ & $10.0002^{* * *}$ \\
\hline Nb Obs. & 115577 & 46406 & 25334 & 14475 \\
\hline Nb Ind. & 14273 & 5450 & 3691 & 1835 \\
\hline$R 2$ & 0.08 & 0.27 & 0.06 & 0.24 \\
\hline
\end{tabular}

Notes: Dagex are age dummies for age $x$; dpyyy are time dummies for year $x$, restricted as in ?. S.e. not shown. ${ }^{* * *} \mathrm{p}<0.01,{ }^{* *} \mathrm{p}<0.05$, * $\mathrm{p}<0.1$. 